\title{
Experimental Investigation on Flexural Performance of Autoclaved Aerated Concrete Slab
}

\author{
Guo-Wei ZHANG ${ }^{1}$, Bo-Shan CHEN ${ }^{1, *}$, Qi-Song MIAO ${ }^{2}$, Hui WU ${ }^{1}$, Peng CHEN ${ }^{1}$
}

${ }^{1}$ Beijing Higher Institution Engineering Research Center of Civil Engineering Structure and

Renewable Material Beijing University of Civil Engineering and Architecture Beijing China 100044

${ }^{2}$ Beijing Building Construction Research Institute Co. Ltd. Beijing China 100039

443783510@qq.com

*Corresponding author

Keywords: Flexural Performance, Cladding Panel, Autoclaved Aerated Concrete.

\begin{abstract}
With the bending experiment of 9 JINYU reinforced autoclaved aerated concrete slabs the objective of the research was to characterize the flexural performance of cladding panel such as deflections and extent of cracking that the elements would undergo under uniform load and finally recommended a suggestion for further analysis. To know more about such non-conventional materials two-point loads were applied to all the specimens and were monotonically increased until failure analyzing how the span affected the flexural behavior. Besides a theoretical analysis was conducted to predict the strength of the AAC panel and the analysis result was in good agreement with the experimental value. Through the experimental analysis it can be seen that AAC panel has the potential to be an excellently energy-saving construction material and is believed to emerge as an alternative to traditional reinforced concrete slab in the near future.
\end{abstract}

\section{Introduction}

\section{The Background}

In recent years a newly-emerging and non-conventional material termed autoclaved aerated concrete slab (AAC) has gained wider acceptance in the construction due to reduce erection time and cost. The raw materials used in production are just as simple as cement lime aluminum water and sand. The dry bulk density of the material ranges from 400 to $800 \mathrm{~kg} / \mathrm{m}^{3}$ and the compressive strength is merely up to $7.5 \mathrm{MPa}$. Such light-weight environment-friendly and energy-saving new wall materials are urgently needed to serve as the external wall panels which are prefabricated in the factory and are installed on construction site as envelop system in order to save the period and speed up the progress. Despite of all the benefits mentioned above one of the perceived advantages with the material is highly fire-resistant and very durable. While there has been decades of research in the China on AAC products the efforts on AAC are still at their infancy and this is far from enough and satisfactory [1].

\section{Research Significance}

At present high-rise residential building urgently needs a large number of reinforced concrete following that plenty of raw materials (cement sand and stone) is greatly consumed. But building materials especially reinforced concrete is in a bad state. It is necessary to make appropriate adjustments for Beijing city. The AAC cladding panel system has the potential to meet the requirement for high-rise building envelopes. According to a recent research at home and abroad the weight of building made by the autoclaved aerated concrete AAC panel may be decreasing a lot when compared with the traditional one creating the fruitful economic benefits. However an especially crucial issue related to failure mode and cost of manufacture has been concerns when high-rise structures use the novel AAC panel as envelop system [2]. 
This paper is focusing on the research of autoclaved aerated concrete cladding panel for envelop system. That engineers fully understand how AAC cladding panels perform during earthquakes is of great significance finally promoting the revolution of new wall materials [3].

\section{Objectives}

The objective of the research was to characterize the flexural behavior of JINYU reinforced autoclaved aerated concrete slabs. In order to gain access to it the research will make certain what assignment should be completed;

1) To observe a full-scale AAC panel's flexural performance under a two-point bending test in terms of failure modes stiffness ductility and record the experimental results in many aspects.

2) To test whether the distribution of AAC strain can satisfy the assumption of plane sections.

3) To analyze how the span affects the flexural behavior.

4) To study load-deformation curve.

Early results from research projects mentioned in this paper have indicated that precast AAC members can potentially be used as non-structural external wall. However there is a need for more extensive and further experimental and analytical studies on structural performance of AAC panel to develop new design guidelines.

\section{Experimental Program}

\section{Panel Prototypes}

All the AAC slabs were obtained from the JINYU factory which complies with the Chinese Standard Specification and this analysis was performed on several randomly-selected images of $3420 \mathrm{~mm} \times 600 \mathrm{~mm} \times 300 \mathrm{~mm}, 3930 \mathrm{~mm} \times 600 \mathrm{~mm} \times 300 \mathrm{~mm}$, and $4350 \mathrm{~mm} \times 600 \mathrm{~mm} \times 300 \mathrm{~mm}$ size. The dry bulk density of the samples had been lowered to $500 \mathrm{~kg} / \mathrm{m} 3$ namely B05 and the strength still kept above 3.5MPa namely A3.5 [3].

Tab. 1 Information of AAC Slabs

\begin{tabular}{|c|c|c|c|}
\hline Specimen no. & Dimension (mm) & Dispose ways of bar & The type of slab \\
\hline A-1 & $3420 \times 600 \times 300$ & $3 \Phi 8.0$ & A3.5 B05 \\
\hline A-2 & $3420 \times 600 \times 300$ & $3 \Phi 8.0$ & A3.5 B05 \\
\hline A-3 & $3420 \times 600 \times 300$ & $3 \Phi 8.0$ & A3.5 B05 \\
\hline B-1 & $3930 \times 600 \times 300$ & $3 \Phi 8.0$ & A3.5 B05 \\
\hline B-2 & $3930 \times 600 \times 300$ & $3 \Phi 8.0$ & A3.5 B05 \\
\hline B-3 & $3930 \times 600 \times 300$ & $3 \Phi 8.0$ & A3.5 B05 \\
\hline $\mathrm{C}-1$ & $4350 \times 600 \times 300$ & $3 \Phi 8.0$ & A3.5 B05 \\
\hline $\mathrm{C}-2$ & $4350 \times 600 \times 300$ & $3 \Phi 8.0$ & A3.5 B05 \\
\hline $\mathrm{C}-3$ & $4350 \times 600 \times 300$ & $3 \Phi 8.0$ & A3.5 B05 \\
\hline
\end{tabular}

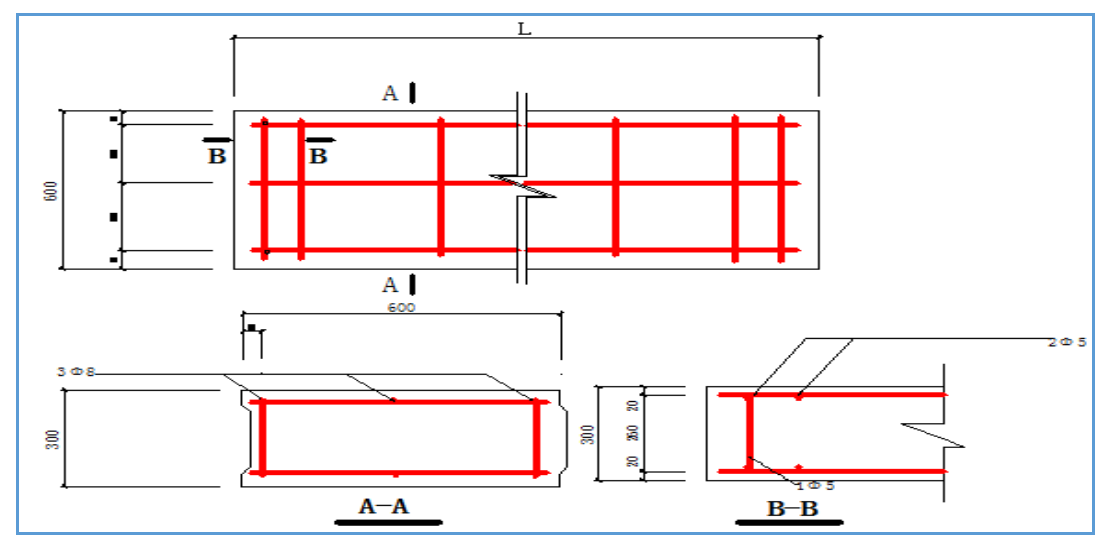

Fig. 1 Reinforcement Form of AAC Slabs 


\section{Test Setup}

The experimental setup consists of loading beam a vertical loading device to imitate wind load digital strain gauges and displacement transducer with least count $0.01 \mathrm{~mm}$. The static load was applied by a hydraulic jack to the specimens through a steel spreader beam. The two-point loading pattern is used to achieve the pure bending. The reinforced autoclaved aerated concrete slab specimen is setup as shown $[4,5,6]$.

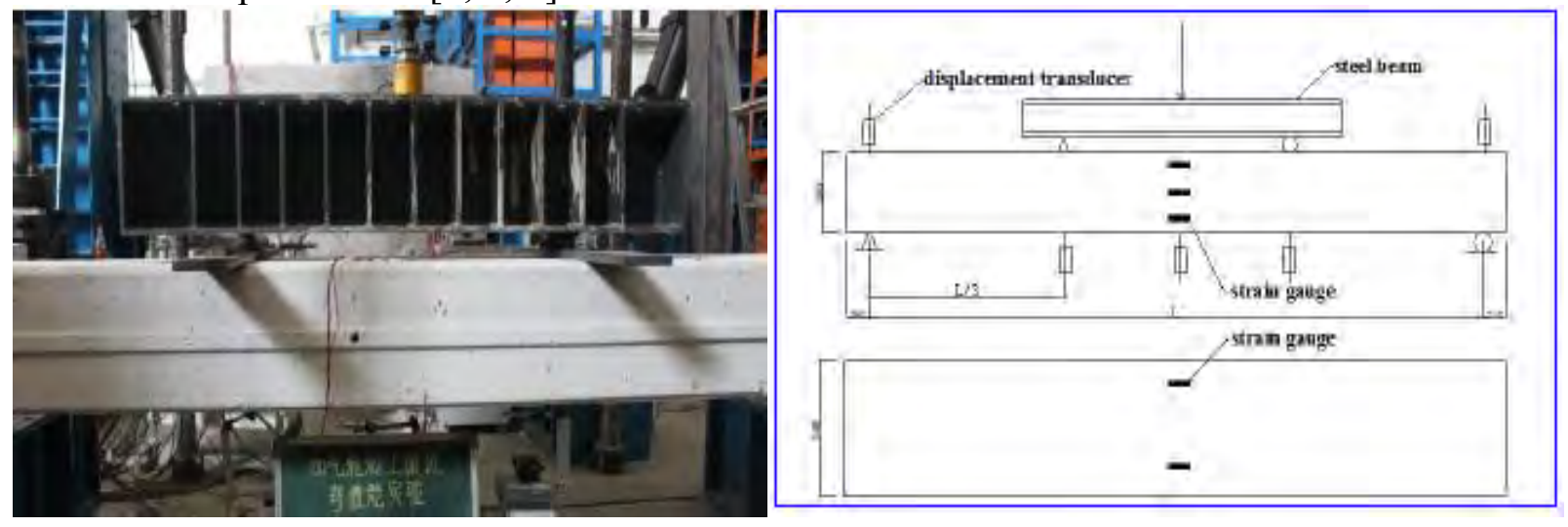

Fig. 2 Test Set-up of the Bending Experiment

\section{Experimental Procedure}

The slab was loaded with a loading rate of $0.05 \mathrm{kN} / \mathrm{S} \sim 0.1 \mathrm{kN} / \mathrm{S}$. Then all the specimens were loaded monotonically up to failure in few minutes. The specimen was considered to have failed when it's bearing capacity dropped to $85 \%$ of the maximum measured load. Observe the failure mode while recording the data. A summary of test result is presented in Table 2

Tab. 2 Information of Specimens

\begin{tabular}{|c|c|c|c|}
\hline Specimens & $\begin{array}{c}\text { Measured Ultimate } \\
\text { load (KN) }\end{array}$ & $\begin{array}{c}\text { Theoretical load } \\
(\mathbf{K N})\end{array}$ & failure mode \\
\hline A-1 & 30.1 & 27.3 & flexure \\
\hline A-2 & 29.9 & 27.3 & flexure \\
\hline A-3 & 31.0 & 27.3 & flexure \\
\hline B-1 & 21.9 & 23.4 & bending-shear failure \\
\hline B-2 & 21.8 & 23.4 & bending-shear failure \\
\hline B-3 & 21.6 & 23.4 & bending-shear failure \\
\hline C-1 & 19.9 & 21.0 & bending-shear failure \\
\hline C-2 & 19.8 & 21.0 & bending-shear failure \\
\hline C-3 & 19.5 & 21.0 & bending-shear failure \\
\hline
\end{tabular}

\section{Experimental Results}

According to test all specimens exhibited a similar cracking behavior at low loading level and the incipient crack occurred in the bending region rightly under the hole. With the increase of the load more cracks were formed with both the mid-span and flexure-shear region and the crack in flexural zone propagated rapidly to $3 / 5$ of the slab height due to lower reinforcement ratio. With the further loading the cracks in the shear span gradually extended towards the loading points. Through experiment phenomenon the major crack of Specimen A-1 is at the mid-span and Specimen A-1 behaved in a ductile manner before failure. 
In particular specimen B-1 and C-1 which have a larger span show a reduction of the crack in the bending region and shear failure occurred in the flexure-shear region. Brittle fracture occurs for Specimen B-1 and C-1 once the cracking moment is reached and no alarm appears before failure. It is worth mentioning that the major crack of Specimen C-1 appears near the vertical tie bar which is the weakest damaged section for crack. Shear failure as is known to all occurs very suddenly and in a brittle fashion. Therefore to avoid the shear failure which is considered as undesirable failure mode the engineers should control strictly shear deformation to escape from sudden and brittle failure $[7,8,9]$.

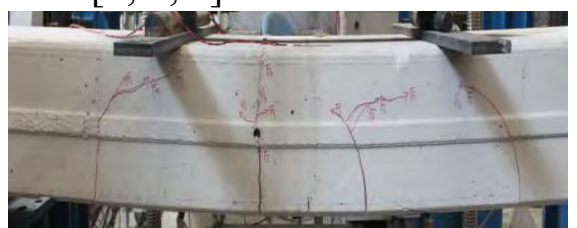

(a) A-1

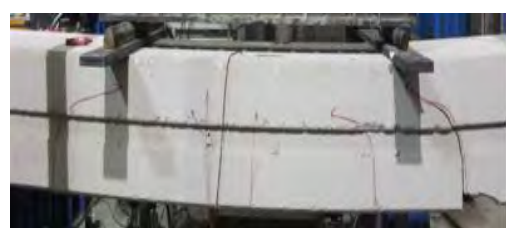

(b) B-1(c)

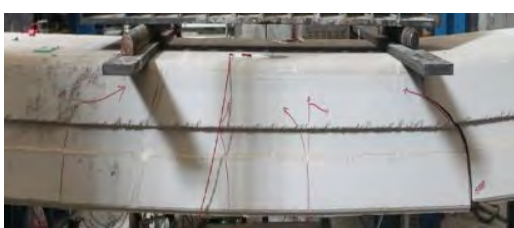

C-1

Fig. 3 Failure Modes and Distribution of Crack

\section{The Load-deflection Curves}

It is observed from Fig. 4 that the bending strength of type A is almost increasing by $20 \%$ when compared with the type $\mathrm{B}$ and that of type $\mathrm{C}$ is the weakest of all. It comes to conclusion that the span of slabs has strong impact on the bending strength. Although with the increase of the span the ductility of AAC slab is becoming better and better load-deflection curves suggested a sharp reduction in strength.
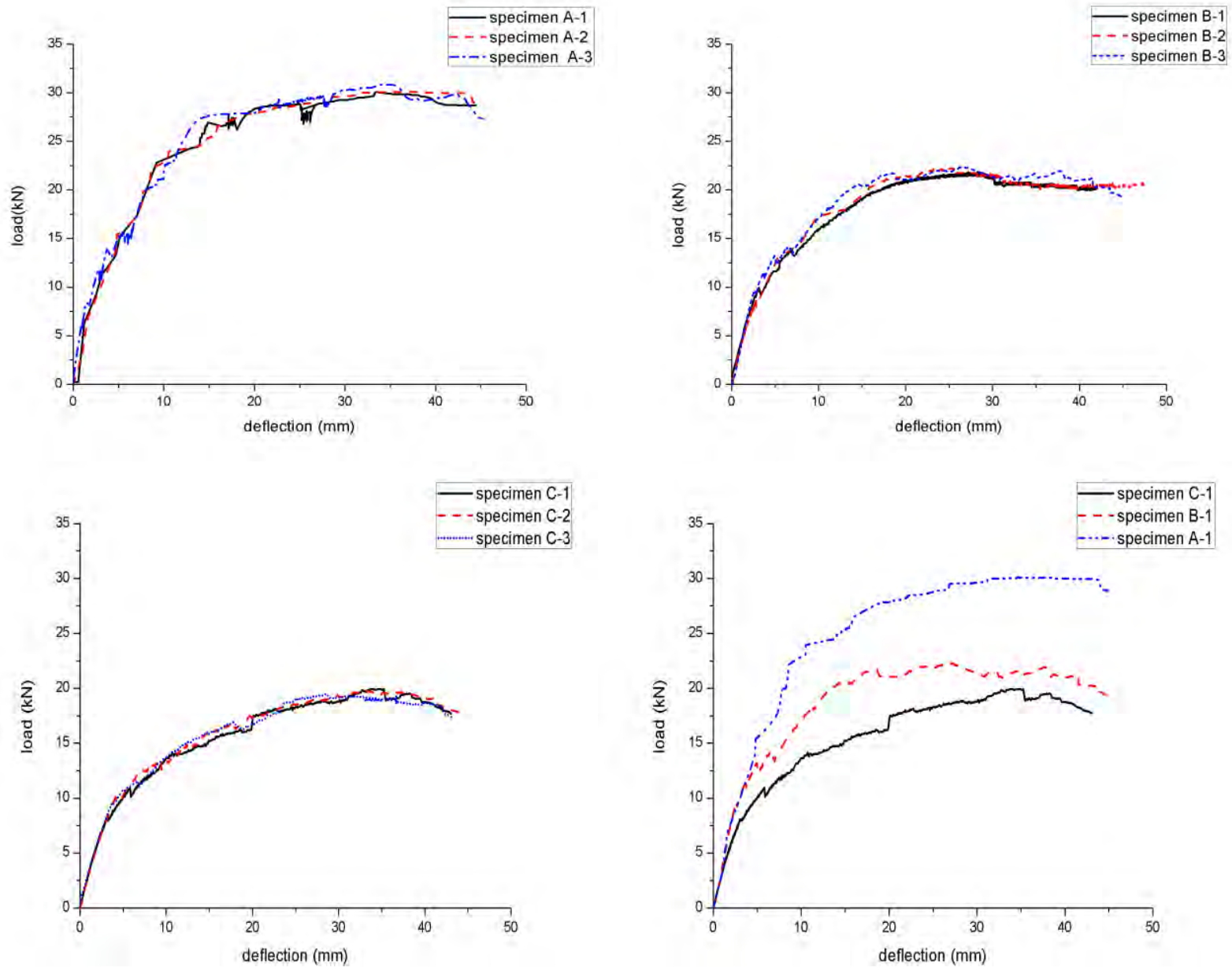

Fig. 4 Load-deflection Curves of AAC Slabs 
From load-deformation curves it can be seen that the AAC slab has great plastic deformation ability and good ductility. When the lateral load was small the load-deflection curves were basically linear and there were no residual deformations after unloading to zero. When the lateral load dropped to $85 \%$ of the ultimate load the panels had lost bearing capacity.

\section{The Theoretical Analysis}

According to the current Technical specification for application of autoclaved aerated concrete the bearing capacity of the normal section of material could be calculated by the following formula and the effect of compression reinforcement is not taken into consideration generally.

$$
M \leq 0.75 f_{c} b x\left(h_{0}-\frac{x}{2}\right)
$$

Where $\mathrm{b}$ is the width of the slab h0 is the effective depth of the section of slab $\mathrm{x}$ is the depth of compressive zone of concrete.

\section{Summary}

As demonstrated the AAC panel has showed a significant increase in the strength and ductility over the traditional reinforced concrete panel.

1) From the load-deformation curve it can be seen that the AAC slab has great plastic deformation ability and good ductility.

2) The increase of the span leads to the decrease of the load carrying capacity.

3) Practice proves that it can be used in the multistory building structure instead of the traditional reinforced concrete panels and surely will have a bright prospect.

4) The distribution of AAC strain can satisfy the assumption of plane sections.

The AAC panel is a promising technique but the research is still in initial stages of development.

\section{Acknowledgement}

The authors would like to express sincere appreciation for my dear teacher Guowei Zhang and Hui $\mathrm{Wu}$. This research is sponsored by BUCEA Urban Rural Construction and Management Industry Research Development Collabration Post Graduate Training Centre. Helps received from staffs and students at the laboratory are also greatly acknowledged.

\section{References}

[1]Nasim Uddin: 'Experimental and analytical study of carbon fiber-reinforced polymer(FRP)/autoclaved aerated concrete (AAC) sandwich panels' Engineering Structures 31 United States 20092337-2344.

[2]Snow C. A comprehensive study of the material properties and structural behavior of AAC products. M.S. thesis. CCEE Department University of Alabama at Birmingham; 1999.

[3]ACI 523.4R-09. Guide for Design and Construction with Autoclaved Aerated Concrete Panels. American Concrete Institute; 2009.

[4]Mousa Mohammed. Optimization of structural panels for cost-effective panelized construction. M.S. thesis. CCEE Department University of Alabama at Birmingham; 2007.

[5]JGJ17-1984. Technical Specification of Autoclaved Aerated Concrete[S]. China Architecture and Building Press Beijing China 2008 (in Chinese).

[6]Wittman F H. Autoclaved Aerated Concrete-Properties Testing and Design (RILEM Recommended Practice) [M]. Spon Press London UK 1993. 
[7]Dembowski J. (2001). A Study of the Material Properties and Structural Behavior of Plain and Reinforced AAC Components MS Thesis CEE Department University of Alabama at Birmingham Alabama.

[8]Yanmin Yang and Hao Zhang: 'Experimental study on flexural behavior of all-lightweight aggregate concrete beams and slabs' In` Key engineering materials'Vol.517 Switzerland2012 51-62.

[9]Xian Li and Henglin Lv: 'Flexural Behavior of Innovative Hybrid GFRP-Reinforced Concrete Beam’ In‘ Key engineering materials'Vol.517 Switzerland 2012 880-857. 